\section{Dement Geriatr Cogn Disord Extra 2011;1:433-438}

DOI: 10.1159/000330929

(c) 2011 S. Karger AG, Basel

Published online: December 24, 2011

www.karger.com/dee

This is an Open Access article licensed under the terms of the Creative Commons AttributionNonCommercial-NoDerivs 3.0 License (www.karger.com/OA-license), applicable to the online version of the article only. Distribution for non-commercial purposes only.

\title{
Criminal Manifestations of Dementia Patients: Report from the National Forensic Hospital
}

\author{
Jeong-Min Kim ${ }^{a, b}$ Kon Chu ${ }^{a, b}$ Keun-Hwa Jung ${ }^{a, b}$ \\ Soon-Tae Lee ${ }^{a, b}$ Sang-Sub Choic Sang Kun Lee ${ }^{a, b}$ \\ ${ }^{a}$ Department of Neurology, Seoul National University Hospital, and ${ }^{b}$ Program in \\ Neuroscience, Neuroscience Research Institute, Seoul National University, Seoul, and \\ 'Department of Psychiatry, National Forensic Hospital, Ministry of Justice, \\ Gong-Ju, South Korea
}

\section{Key Words}

Dementia $\cdot$ Violence $\cdot$ Crime $\cdot$ Behavioral disorders

\begin{abstract}
Background/Aims: Some dementia patients have profound behavioral and psychological symptoms which might cause legal violation. We illustrate clinical and criminal characteristics of dementia patients who had been incarcerated because of criminal activity. Methods: The National Forensic Hospital is the only hospital-based correctional facility in the Republic of Korea which incarcerates criminals with psychiatric or neurological disease. Between May 2008 and April 2009, those patients who had been diagnosed with dementia in the National Forensic Hospital were included in the study. We reviewed their medical and legal reports. Results: There were 7 dementia patients out of 752 patients, including 2 Alzheimer's disease (AD) patients, 1 vascular dementia patient, and 4 patients with alcohol-related dementia. Criminal behavior included simple larceny by the 2 AD patients, and multiple violent crimes in a drunken state by the other 5 patients. Conclusions: This study reported diverse criminal behaviors among dementia patients. Inebriation may be related to violent criminal behavior among some dementia patients.

Copyright $\odot 2011$ S. Karger AG, Basel
\end{abstract}




\section{Introduction}

The present time is characterized by a rapid increase in the aged population. As the elderly population expands, it is conceivable that various unexpected problems concerning dementia patients will be encountered. Abusive or criminal behavior toward dementia patients has been a major concern in countries with aging populations, and warrants adequate action for the protection of dementia patients [1]. On the other hand, it may be also possible that legal violation by dementia patients will become another distressing problem in the future, considering that behavioral and psychosocial dysfunction are sometimes associated with patients with advanced dementia $[2,3]$. Several studies have reported increased aggressive behavior in dementia patients compared with the normal population [4]. Another study reported that the most common medical condition in elderly criminals was alcohol abuse, followed by dementia [5]. A transgenic animal model of Alzheimer's disease (AD) showed increased violence compared with wild-type animals [6]. It may be important to find potential factors triggering criminal behavior in dementia patients to prevent unwanted sequelae. In this study, we reviewed criminal cases committed by 7 dementia patients in various situations and suggested possible criminogenic risk factors.

\section{Patients and Methods}

The National Forensic Hospital is the only hospital-based correctional facility in the Republic of Korea that incarcerates criminals with psychiatric or neurological disease. Those criminals who have committed crimes as a manifestation of their psychiatric or neurological disease in South Korea are sent to this forensic hospital by the court system. The majority of the incarcerated criminals were diagnosed with psychiatric diseases including schizophrenia, bipolar disorder, and major depressive disorder (92.8\%). Other minor diseases include intellectual disability, epilepsy, dementia, and substance abuse. When a patient with progressive cognitive decline is admitted, we perform the Seoul Neuropsychological Screening Battery (SNSB) including mini-mental status examination (MMSE), electroencephalography, and brain magnetic resonance imaging (MRI). We also perform blood tests including those for thyroid function, Venereal Disease Research Laboratory titer, human immunodeficiency virus antibody, vitamin B, and folate level. Dementia diagnosis is made according to the Diagnostic and Statistical Manual of Mental Disorders, $4^{\text {th }}$ edition (DSM-IV) guidelines by a neurologist and psychiatrist. Dementia subtype is determined according to the criteria from the National Institute of Neurological and Communicative Disorders and Stroke and the Alzheimer's Disease and Related Disorders Association, DSM-IV guideline, and Oslin's criteria [7]. Once the diagnosis is made, we measure global deterioration scale (GDS), Hachinski score, and clinical dementia rating (CDR) regularly. Between May 2008 and April 2009, the dementia patients who had been incarcerated in the National Forensic Hospital were enrolled in this study. We retrospectively reviewed their medical and legal reports. Violent crime was defined to include homicide, attempted murder, rape, assault, arson, and robbery. This study was reviewed and approved by the institutional review board of the National Forensic Hospital in Korea.

\section{Results}

There were a total of 7 dementia patients out of 752 incarcerated prisoners. The age spectrum of dementia patients was between 54 and 63 years, and there was 1 female patient. Clinical characteristics of the dementia patients are indicated in table 1. The range of MMSE scores 
Table 1. Clinical and criminal characteristics of dementia patients

\begin{tabular}{|c|c|c|c|c|c|c|c|c|c|c|c|}
\hline No. & Age & Sex & Dementia & Crime & $\begin{array}{l}\text { Previous } \\
\text { crime }\end{array}$ & Alcohol & MMSE & GDS & $\mathrm{CDR}$ & $\begin{array}{l}\text { Hachinski } \\
\text { score }\end{array}$ & Brain MRI \\
\hline 1 & 57 & $\mathrm{M}$ & ARD & Murder & 3 & Yes & 24 & 3 & 1 & 4 & Left frontal atrophy \\
\hline 2 & 54 & $\mathrm{M}$ & ARD & Assault & 6 & Yes & 21 & 4 & 1 & 0 & Both frontal atrophy \\
\hline 3 & 54 & $\mathrm{M}$ & ARD & Assault & 1 & Yes & 23 & 3 & 1 & 0 & Right frontotemporal atrophy \\
\hline 4 & 62 & $\mathrm{M}$ & ARD & Attempted murder & 2 & Yes & 20 & 6 & 3 & 3 & Diffuse brain atrophy \\
\hline 5 & 66 & M & VD & Attempted murder & 0 & Yes & 16 & 4 & 2 & 8 & $\begin{array}{l}\text { Multiple lacunae, right frontal } \\
\mathrm{ICH} \text {, left frontal meningioma }\end{array}$ \\
\hline 6 & 60 & $\mathrm{M}$ & $\mathrm{AD}$ & Larceny & 0 & No & 17 & 5 & 3 & 1 & Both temporal atrophy \\
\hline 7 & 65 & $\mathrm{~F}$ & $\mathrm{AD}$ & Larceny & 0 & No & - & 7 & 5 & 0 & Both frontotemporal atrophy \\
\hline
\end{tabular}

$\mathrm{ARD}=$ Alcohol-related dementia; $\mathrm{VD}=$ vascular dementia; $\mathrm{AD}=$ Alzheimer's disease; $\mathrm{MMSE}=$ mini-mental state examination; GDS = global deterioration scale; $\mathrm{CDR}=$ clinical dementia rating; $\mathrm{ICH}=$ intracerebral hemorrhage.

was $16-24$, and dementia subtypes included 2 probable AD patients, 1 vascular dementia (VD) patient, and 4 alcohol-related dementia (ARD) patients. Five patients (ARD+VD) had a history of harmful use of alcohol and had experienced at least one episode of head trauma. The VD patient had experienced two episodes of ischemic stroke and one hemorrhagic stroke. He was also diagnosed with a meningioma on his left frontal convexity, which was removed by surgical treatment after admission. SNSB showed that all the patients had considerable frontal lobe dysfunction, and brain MRI disclosed various degrees of atrophic change because of head trauma, stroke, and probably dementia itself (fig. 1). No patient had clinically significant findings on their blood serum tests. One $\mathrm{AD}$ patient progressed considerably during her incarceration such that her sentence was suspended and she was transferred to a nursing hospital after 5 years. However, the progression of 4 ARD patients was relatively slow or stationary, although cognitive function was not restored after a prolonged period of alcohol abstinence.

Criminal profile and social background are also illustrated in table 1. The mean age of the first crime was $53.6 \pm 8.8$ years, and 4 patients committed multiple crimes. One patient committed a total of six violent crimes. Criminal behaviors were clearly distinguishable between the two groups. The first group of 5 patients who had been diagnosed with ARD or VD committed violent crimes including murder, attempted murder, arson, and assault. All of the patients were in a heavily drunken state combined with delusional ideas during their criminal behavior. One patient killed 2 family members in a drunken state without noticeable intention, and he did not remember his criminal behavior after his arrest. Two patients attempted to kill their neighbors because they wrongly thought the neighbors were trying to seduce their wives. The other 2 assaulted pedestrians because of persecutory delusion. The second group of $2 \mathrm{AD}$ patients committed simple larceny; 1 patient tried to steal a piece of bread, and the other patient tried to drive a neighbor's truck to go to a supermarket. They were not drunk during their criminal behavior; instead they had incidentally lost contact with their family members and had starved for a long time. They had remarkable weight loss and a filthy appearance on admission.

Memantine was prescribed to all the patients to maintain cognitive function, and they were well maintained without adverse effect. Four ARD patients displayed intermittent aggression and various psychotic symptoms including hallucinations or persecutory delusions, which were controlled after low-dose antipsychotic treatment. However, 1 patient developed a neuroleptic malignant syndrome and had to stop medication. A selective serotonin receptor inhibitor and an antiepileptic were also prescribed to control behavioral and psychological symptoms. Three patients were prescribed a fluoxetine, but 1 patient experienced aggravated agitation and obsessive behavior. Valproate was prescribed to 3 patients, who were well maintained without adverse reaction. 

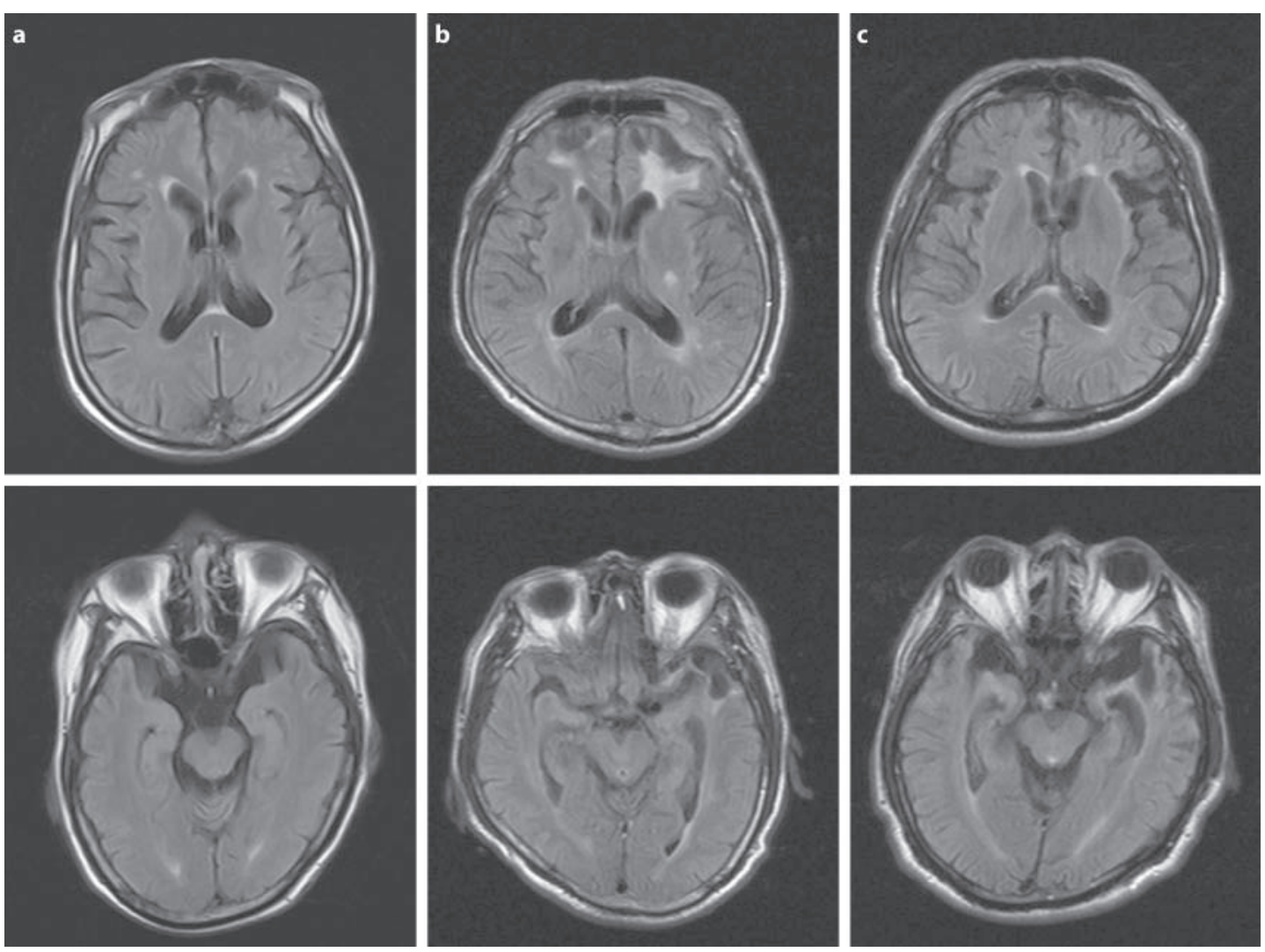

Fig. 1. Representative brain MRI of dementia patients. a Patient A was diagnosed with alcohol-related dementia, and MRI reveals widened ventricles and diffuse brain atrophy. b Patient B was a patient with vascular dementia, and MRI shows multiple ischemic lesions and right frontal hemorrhage. This was combined with left frontal meningioma, which was successfully removed during incarceration. c Patient $\mathrm{C}$ was an Alzheimer's disease patient with profound naming difficulty. MRI revealed left dominant temporal lobar atrophy.

\section{Discussion}

Patients with dementia who committed a crime were found to have various dementia subtypes and states of progression. Criminal behaviors by dementia patients can be categorized into violent and nonviolent crime. Alcohol-drinking dementia patients tended to commit violent crimes, whereas patients without alcohol intake history committed nonviolent crimes.

Although dementia progression states were diverse on the whole, AD patients tended to be in a more advanced stage in terms of MMSE and CDR scores compared with ARD patients. We suspect that alcohol-related crimes took place in an early stage of dementia as a result of hallucinations, delusions, and executive dysfunction caused by inebriation, whereas patients without alcohol consumption committed a crime in a later stage when dementia had progressed considerably and they had lost most of their socioeconomic and familial support. Deteriorated frontal lobe function has been suggested as a biological risk factor for violent and antisocial behavior among criminals [8]. Alcohol dependence is known to decrease frontal cerebral blood flow, distracting frontal executive function [9]. Another study showed that the neuropsychological profile of ARD patients exhibited a similar de- 
gree of frontal executive deficits as VD patients [10]. It may be justifiable to carefully assess and control alcohol consumption habits for a subset of dementia patients who have committed a violent crime.

Behavioral and psychological symptoms in dementia patients are known to develop independently from cognitive decline, and cause a substantial burden to family members [11]. Five out of 7 patients did not have regular family contact before admission, because 3 ARD patients had exhibited profound behavioral disturbance causing excessive trouble to their family, and the other $2 \mathrm{AD}$ patients were incidentally lost from their family. Those $2 \mathrm{AD}$ patients might not have committed a crime if the basic necessities of life had been provided. The patients without family contact had to remain incarcerated longer than their sentence because no one could take care of them outside of the forensic facility. One patient had to remain more than 5 years after she had stolen a piece of bread because no caregiver could be found for her. She was finally transferred to a nursing hospital when dementia progressed terminally such that she could not swallow food by herself. The medical problems posed by the geriatric forensic population present a challenge to forensic hospitals and correctional facilities [5]. The forensic hospital is supposed to incarcerate and correct criminals with a mental or neurological disease, but it will become a hospice shelter for homeless dementia criminals if adequate action is not taken. Several studies have shown that the provision of housing reduces hospital visits, admissions, and duration of hospital stay among homeless individuals, as well as overall public system spending [12-14]. Similar approaches might be helpful for homeless dementia criminals.

Two major limitations of this study are the insufficient number of patients and the selection bias. There could be more dementia patients with criminal behaviors in their homes or hospice shelters that were not accused by victims. Selection bias may have taken place by a court system since the court ultimately decides the referral of dementia criminals to the forensic hospital. Considering that the diagnostic criteria of ARD are still controversial, the 4 ARD patients in our reports may have another type of dementia.

This preliminary case series described diverse criminal behaviors by dementia patients. Although it is difficult to generalize our results, it is suggested that loss of family contact and social deprivation might lead to incidental criminal activity in dementia patients, and inebriation may be related to more severe violent crime. Alcohol restriction programs and social safety nets may be helpful to prevent future criminal behavior by dementia patients.

\section{Acknowledgement}

This study was supported by a grant of the Korea Healthcare Technology R\&D Project, Ministry of Health and Welfare, Republic of Korea (A101535).

\section{Disclosure Statement}

The authors report no conflict of interest. 


\section{References}

-1 Cooper C, Selwood A, Blanchard M, Walker Z, Blizard R, Livingston G: Abuse of people with dementia by family carers: representative cross sectional survey. BMJ 2009;338:b155.

-2 Shimabukuro J, Awata S, Matsuoka H: Behavioral and psychological symptoms of dementia characteristics of mild Alzheimer patients. Psychiatry Clin Neurosci 2005;59:274-279.

-3 Finkel SI, Costa e Silva J, Cohen G, Miller S, Sartorius N: Behavioral and psychological signs and symptoms of dementia: a consensus statement on current knowledge and implications for research and treatment. Int Psychogeriatr 1996;8:497-500.

4 Nguyen VT, Love AR, Kunik ME: Preventing aggression in persons with dementia. Geriatrics 2008; 63:21-26.

5 Lewis CF, Fields C, Rainey E: A study of geriatric forensic evaluees: who are the violent elderly? J Am Acad Psychiatry Law 2006;34:324-332.

-6 Alexander G, Hanna A, Serna V, Younkin L, Younkin S, Janus C: Increased aggression in males in transgenic Tg2576 mouse model of Alzheimer's disease. Behav Brain Res 2011;216:77-83.

7 Oslin DW, Cary MS: Alcohol-related dementia: validation of diagnostic criteria. Am J Geriatr Psychiatry 2003;11:441-447.

-8 Blake PY, Pincus JH, Buckner C: Neurologic abnormalities in murderers. Neurology 1995;45:16411647.

-9 Noël X, Sferrazza R, Van Der Linden M, Paternot J, Verhas M, Hanak C, Pelc I, Verbanck P: Contribution of frontal cerebral blood flow measured by $(99 \mathrm{~m}) \mathrm{Tc}$-Bicisate spect and executive function deficits to predicting treatment outcome in alcohol-dependent patients. Alcohol Alcohol 2002;37: 347-354.

-10 Schmidt KS, Gallo JL, Ferri C, Giovannetti T, Sestito N, Libon DJ, Schmidt PS: The neuropsychological profile of alcohol-related dementia suggests cortical and subcortical pathology. Dement Geriatr Cogn Disord 2005;20:286-291.

-11 Borson S, Raskind MA: Clinical features and pharmacologic treatment of behavioral symptoms of Alzheimer's disease. Neurology 1997;48:S17-S24.

-12 Larimer ME, Malone DK, Garner MD, Atkins DC, Burlingham B, Lonczak HS, Tanzer K, Ginzler J, Clifasefi SL, Hobson WG, Marlatt GA: Health care and public service use and costs before and after provision of housing for chronically homeless persons with severe alcohol problems. JAMA 2009;301: 1349-1357.

-13 Kyle T, Dunn JR: Effects of housing circumstances on health, quality of life and healthcare use for people with severe mental illness: a review. Health Soc Care Community 2008;16:1-15.

$\checkmark 14$ Culhane D, Metraux S, Hadley T: Public service reductions associated with placement of homeless persons with severe mental illness in supportive housing. Housing Policy Debate 2002;13:107-163. 